\title{
Power Supply Fluctuation and Sales Performance of Frozen Foods Business: A Study of ABA Metropolis. Nigeria
}

\author{
Ezenta, Ogemdi Nneoma \\ Department of marketing, University of Nigeria, Enugu Campus - Nigeria \\ Osagie Leslie Uwabor Ph.D* \\ Department of Accounting, School of Business Education, Federal College of Education (Technical) \\ Omoku. Rivers State. Nigeria \\ P.M.B 488 Uniport Post Office, Port Harcourt Nigeria \\ Okoroafor, Chimaeze \\ Department of Marketing, College of Management Sciences \\ Michael Okpara University of Agriculture, Umudike. Abia State \\ Ordu, Blessing Chinwe Nchelem \\ Department of Accounting, School of Business Education \\ Federal College of Education (Technical) \\ Omoku. Rivers State. Nigeria
}

\begin{abstract}
One of the essential requirements for output growth in the frozen food business is adequate electricity supply. The electricity supply bane has brought about the acquisition of expensive power back up facilities in the form of plants, generators, and inverters to augment stable electricity supply. The study therefore, investigated power supply fluctuation and sales performance of frozen foods in Nigeria. In line with the objectives of the study, two hypotheses were formulated. The descriptive survey research design was adopted for the study. The population of the study comprised of twenty (20) frozen food firms in Aba with a sample size of sixty (60) respondents which was conveniently drawn from our population of interest. A structured questionnaire based on the fivepoint Likert scale was used in data collection. Frequency and percentages were used in analysing both the personal data of the respondents. While Kendall tau_b was employed in analyzing the hypotheses formulated. The findings revealed that a significant relationship exists between erratic power supply and profitability; alternative source of power supply and profitability. We therefore, recommended amongst others that, Government should encourage competition in the power sector, rather than the monopoly the electricity company is currently enjoying. They need to be proactive and embrace the renewable energy which would lead to decentralization of power supply, create more jobs, lead to lower costs, and cleaner environments.
\end{abstract}

Keywords: Power, supply, fluctuation, erratic power supply, alternative power supply, profitability, sales performance

DOI: $10.7176 / \mathrm{EJBM} / 13-15-02$

Publication date:August $31^{\text {st }} 2021$

\section{Introduction}

In Nigeria, and perhaps Aba in the South-East region, it's a phenomenon that as soon as there is short of power supply, a substitute called fuel or diesel generator is been used. In homes, offices, churches, mosques, social gatherings and even market area, it has become a norm for everyone to use generator due to unreliable power supply system in the country. Currently, about $90 \%$ of businesses and $30 \%$ of homes is powered by generator in Nigeria (NiyiAwofeso, 2011).

As businesses and homes grapple with power supply, the region's utility company Enugu

Electricity Distribution Company (EEDC) has attributed the development to very low power generation in the entire country. This has given rise to massive load-shedding by the Transmission Company of Nigeria (TCN). This means that businesses that depend heavily on public power supply will experience epileptic supply of power due to load-shedding thereby encouraging the massive use of generator as an alternative source of power supply.

The usage of generator seems to be the best available alternative to setting up an effective frozen food business in Nigeria because when compared to solar energy or biogas converter. This is because it is affordable and easy to operate with any prior knowledge about technology. However, most frozen food businesses in Aba do not understand the overall effect of generator usage, some only realise that maintaining a generator system (such as cost of fuelling) is a challenging factor compared to when using the National functional grid.

The demand for electricity in Nigeria far outstrips the supply thereby hindering the country's development, 
notwithstanding the abundance of energy resource across the country (Ajao, Ajimotokan, Popoola, \&Akande, 2009). Economic wise, the nation suffers loss due to business depending more on use of generator. This increases the cost of operation and in turn making services provided quite expensive in a country where only about 61.2\% lives below World poverty standard (This Day Live, 2013). Furthermore, the dependence on generator for alternative power supply has crippled frozen food businesses which are a key integral for any economic development.

Frozen food business has gradually but steadily grown to become one of the fastest growing industries in Nigeria over the years. The business owes its top flight status to the continually growing population, and the increasing bustling nature of average Nigerian family, especially those with a working class status. Operating frozen food businesses can be lucrative and competitive especially in a commercial city like Aba. Shortage of power supply can also discourage people from starting frozen food business. Frozen food business has to do with the preservation of livestock food such as beef, fish, turkey etc in the refrigerator to keep it fresh for consumption on a later date. Without access to electricity, one will not be able to power the storage devices and as such, be heading to a major loss as supplies are perishable. Several frozen food businesses are closing everyday in Aba, some are at the verge of collapsing due to inadequate power supply. Unreliable power supply is a major disincentive to starting frozen food business.

According to Sambo, adequate energy has a major impact on the modern day life and will also improve the Nigeria's development to be able to compete on the international market level (2008). There is only about $40 \%$ of Nigeria's population having access to electricity which indicates the reason for low rate of development after her independence since 1960 (Iwori, 2008). Steady power supply is the basic mover of technology and social development, and hardly any enterprise or indeed any aspect of human that does not require energy in one form or the other (Olawale\&Garvwe, 2010).

From experience, it is easy to identify an industrial or market area in Nigeria due to the noise coming from generator usage. There is however limit to amount and level of noise an individual is expected to be exposed to per day. The situation of people working in such environment can be critical knowing that they are exposed to an increasing level of noise from generator on daily basis. It is known that noise has effect on human system by reducing her thinking ability and IQ when exposed to noise daily over a long time range, and also causes sleep and psychological disorders (RaunoPaakonen, 2012). Currently, there are no measurements for noise level on most of the generators used in market areas in Nigeria. The health risk associated with generator usage is also to be considered, knowing that operating generator requires the use of diesel or fuel which is products from fossil fuel.

Many studies have been carried out on the relationship between power supply instability with other construct and practices. For instance, Lassana \& Abdoulaye (2013) studied electric power outage and the productivity of small and medium enterprises in Senegal. Ketelhout (2008) investigated the impact of electricity crisis on consumption behaviour of small and medium enterprises. Olayemi (2012) looked at electricity crisis and manufacturing productivity in Nigeria (1980-2008). It is on this background that this study seeks to investigate the erratic nature of power supply and the sales performance of frozen food business in Aba metropolis, Nigeria.

\section{Statement of the Problem}

The rate of power supply failure in Nigeria is quite alarming. It has become a major cause of concern for a frozen food business owner as the business is almost, completely dependent on electricity. Businesses that do not have access to power will lose a lot as their supplies are perishable. The inadequate power supply with limited access to electricity from the national grid system has caused individuals and many businesses to self-generation of electricity supply; the most available means is the diesel fuel generator. The recent power crisis experienced in the country is hurting business owners' confidence thereby pushing businesses to the brink of collapse. It slows their growth while increasing their energy cost. While some are taking austere measures to survive; others who cannot bear the adverse effect of the situation have folded up. Studies on power supply and sales performance are limited. For instance, (Ogbuagu, Ubi \& Effiom, 2010; Maleko, 2005) who looked at impact and structure of electricity supply on microenterprise in rural areas have not considered its impact on sales performance perhaps of frozen food business. Based on the above stated facts, there exist a point of departure to empirically investigate the erratic power supply and sales performance of frozen food business in Aba metropolis, Nigeria.

\section{Objectives of the Study}

The main objective of this study is to investigate the effect of power supply fluctuation on sales performance of frozen food in Aba metropolis, Nigeria. The following specific objectives are;

1. To examine the effect of erratic power supply on the sales performance of frozen food business in Aba metropolis. 
2. To evaluate the influence of alternative sources of power supply on the sales performance of frozen food business in Aba metropolis.

\section{Research Questions}

The following are the research questions to be addressed by this study;

1. To what extent does erratic power supply affect the sales performance of frozen food business in Aba metropolis?

2. To what extent does an alternative source of power supply influence the sales performance of frozen food business in Aba metropolis?

\section{Research Hypotheses}

Based on the objectives and research questions above, the following null hypotheses have been formulated for the study;

$\mathrm{H}_{1}$ : There is no significant relationship between erratic power supply and profitability of frozen food business in Aba metropolis.

$\mathrm{H}_{2}$ : There is no significant relationship between alternative sources of power supply and profitability of frozen food business in Aba metropolis.

\section{Literature Review}

Electricity is the flow of electrical power or charge. It is a secondary energy source which means that we get it from the conversion of other sources of energy like coal, natural gas, oil, nuclear power and other natural sources, which are called primary sources. The energy sources of electricity can be renewable or non-renewable, but electricity itself is neither renewable nor non-renewable. (McGraw-Hill Encyclopaedia of Science \& Technology, 2002) Electricity is a basic part of nature and it is one of our most widely used forms of energy. Many cities and towns were built alongside waterfalls (a primary source of mechanical energy) that turned water wheels to perform work. Before electricity generation began over 100 years ago, houses were lit with kerosene lamps, food was cooled in iceboxes, and rooms were warmed by wood-burning or coal-burning stoves.

Electricity is one of the cheapest forms of energy that is obtainable by industries and domestic users all over the world. It has also become one of the essential requirements for increase in productivities in manufacturing sector. This is because it serves both the function of diesel and fuel to operate machinery (Ellahi, 2011). Electricity has long been considered as an incentive for enhancing economic growth. For developing nations, the growth in the utilization of energy is directly and closely related to expansion in industrialisation (World Bank, 2005).Mohammed (2013) opined that electricity boosts and triggers investment for economic development. However, electricity generation and supply in Nigeria has not really expanded industrialisation as perceived by World Bank (2005).

Electric power supply system in a country comprises of generating units that produce electricity; high voltage transmission lines that transport electricity over long distances; distribution lines that deliver the electricity to consumers; substations that connect the pieces to each other; and energy control centres to coordinate the operation of the components. Electricity is a significant component of virtually any production process. As such, limited supply has the potential to, directly and/or indirectly; affect the economic activities of firms. In documenting such a crucial economic role of energy, a common approach in the literature is to measure the output loss associated with electricity outages. One of the analytical frameworks used is a production function in which electricity contributes directly to firms' output as a separate input, and indirectly as a determinant of the extent to which other direct inputs such as capital equipment is used (Adenikinju, 2005).

An alternative approach, a subjective method, is based on self-assessment by which surveys ask firms to quantify the loss they incur due to power outages. This approach relies on the assumption that firms well positioned to provide relatively accurate valuation of how much it cost them to replace more frequently or to repair damaged machinery or equipment, or to assess the lost output due to idled inputs. A simple approach to evaluate the costs of power outages consist of just aggregating the cost amounts provided in the survey. However, many biases can plague the outcome, since firms may have the tendency to overestimate the incurred costs, hence, over-emphasizing the constraint that electricity poses to their business activity (Uchendu, 1993).

\section{Study Variables and Research Framework}

In this study, power supply fluctuation is our predictor variable while sales performance is our criterion variable. The attributes of these variables are erratic power supply, alternative sources of power, and profitability respectively. 


\section{Operational Framework of the Study}

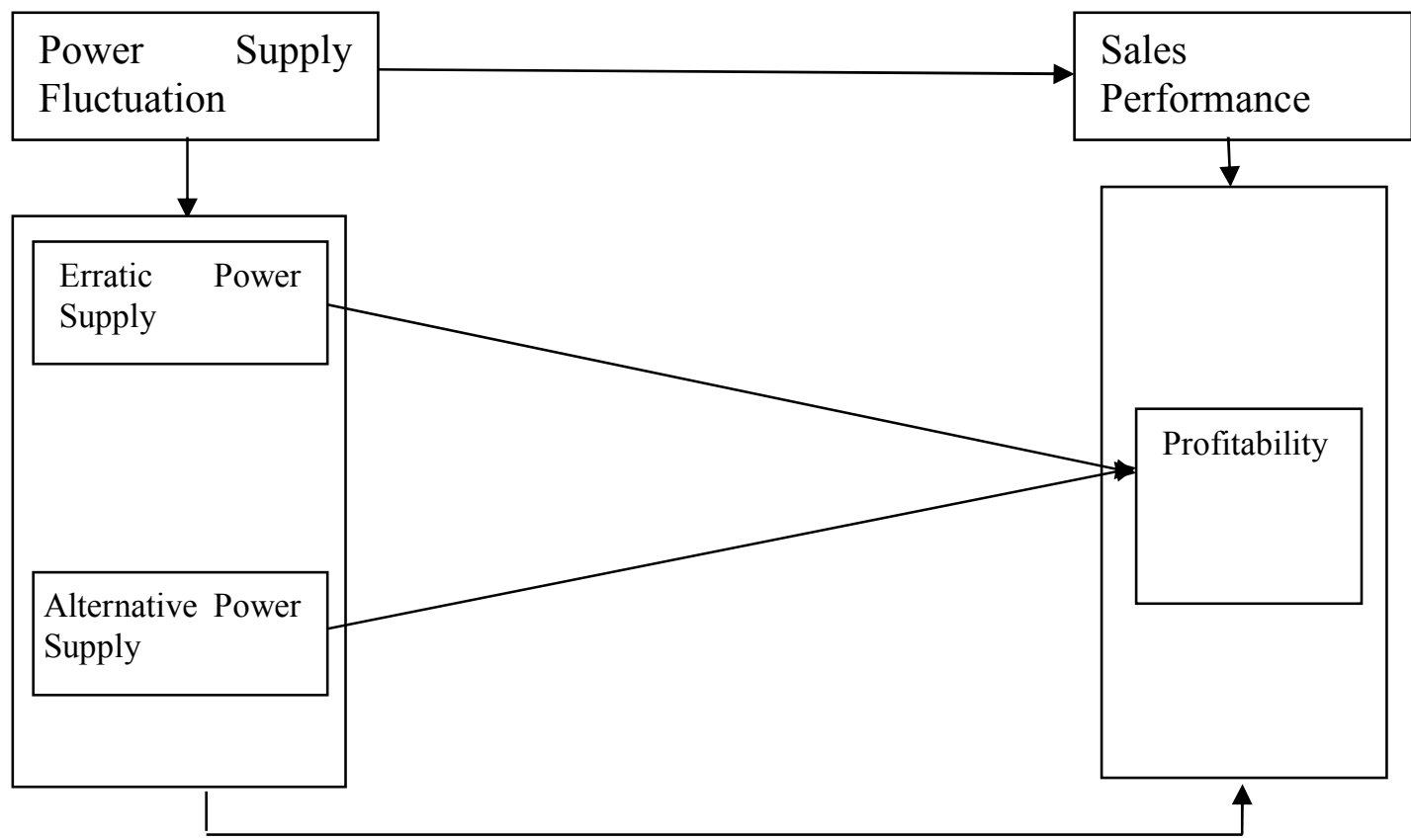

Figure2: Operationalization of the Relationship between Power Supply Fluctuation and Sales Performance of Frozen Food.

Source: Desk Research 2021

\section{Electricity Power Supply and Sales Performance}

"Electricity is today's most important energy form for small and medium, and large-scale businesses. Secure supply of electricity at transparent market prices, and high and well-defined quality standards are crucial to economic growth and our whole way of life. Energy supplies have a significant impact on economic activities" (Velasquez and Pitcher, 2010). This is because it is used for diverse purposes extending from production, storage, powering of office equipment and product display. Access to power enlarges the number and diversity of business and job prospects available. Electricity means that businesses, such as hair salons, bakery and welders, all of which rely on energy to function. Energy also leads to the formation of new markets, businesses and job openings, which offer more opportunities for individuals to earn an income and lift them, their families and their communities out of poverty. Electricity provides business owners with access to online information and resources. Power provides business owners with information that is critical to operating their business successfully, whether that information is about local or national markets, new economic policies or tax regulations. This allows small business owners in rural areas to involve the wider business community and learn best practices from other individuals working in the same industry (Maleko, 2005).

A lack of a "consistent access to reliable power costs businesses and the economy as a whole. Even with access to energy, unreliable power makes operating a business even more challenging than usual. African manufacturing enterprises experience power outages 56 days a year on average. As a result, firms lose six percent of sales revenues in the informal sector. Where back-up generators are limited, losses can be as high as 20 percent. These losses have severe consequences for the health and growth of the wider economy, not to mention the dramatic impact in achieving other development objectives outlined by the Millennium Development Goals"(Gretchen, 2013).

\section{Erratic Power Supply and Sales Performance}

Erratic power supply refers to short or long term loss of electric power to an area (Ama, 2012).The supply of elecricity in Nigeria is bedevilled with consistent crisis as exemplified by such indicators as electricity blackouts and persistence on self-generating electricity. Indeed as noted by Ekpo (2009), Nigeria is running a generator economy with its adverse effects. Ndebbio (2006) argued that electricity supply drives industrialization process. He submitted that one important indicator whether a country is industrialized or not is the megawatt of electricity consumed. He further argued that a country's electricity consumption per-capita in kilowatt hours (KWH) is proportional to the state of industrialization of that country.

Ukpong (1976) established the existence of a positive relationship between electricity consumption and economic development. In addition, he submitted that the expansion of energy sector on the demand side is 
important factor in accelerating the growth of the industrial sector. Ekpo (2009) elaborated on the folly of running a generator economy and its adverse effects on investment. He strongly argued that for Nigeria to jump start and accelerate the pace of economic growth and development, the country should fix her power supply problem. Aigbokan (1999) argued in his paper that fixing the energy sector is tantamount to shifting the production possibility curve of the country's economy .Adenikinju (2005) provided a strong argument to support the importance of energy supply. The poor nature of electricity supply in Nigeria, he argued, has imposed significant cost on the industrial sector of the economy. This result corroborates the survey of the Manufacturers Association of Nigeria (MAN) 2005. In that survey MAN indicated that the costs of generating power constitute about 36 percent of production.

\section{Empirical Review}

Aderemi, Ilori, Aderemi \& Akinbami, (2009) studied the "Assessment of electrical energy use efficiency in Nigeria food industry". This study examined various patterns of energy consumption; it identified the sources of energy wastage, and assessed the effectiveness of the strategies that were employed to reduce energy waste in the food companies. Random sampling technique was used to select the food companies in South-western Nigeria which represent more than $50 \%$ of the Nigerian food and beverage companies. Structured questionnaire, interview and direct observation were employed as research instruments. Analytical procedure as given by Knutson and ANSI/NEMP for calculating electrical energy lost to heat per hour $(\mathrm{Wh} / \mathrm{h})$ and power factor respectively was adopted for the study. The study showed that the pattern of electrical energy consumption in the food companies was mainly from generating set; this was due to either low voltage or epileptic power supply from national grid. The study concluded that the factors that constituted electrical energy waste and energy use inefficiency in the food companies in the study area were very identical and recommendations for effective energy use efficiency in the firms were proposed. This study only concentrated its effort on examining the electricity use and consumption without relating it with the performance measure to determine the output in Nigeria food industry.

Toyin, (2014)The Effects Of Electricity Power Outage On The Provision Of Electronic Newspaper Services Samuel Adegboyega University, Ogwa, Edo State, Nigeria. The study examined effects of electricity outage on e-newspaper services in university libraries in Nigeria with Samuel Adegboyega University, Ogwa, Edo State as a case study. The study employed the use of questionnaire as the instrument for data collection. 40 staff members of Samuel Adegboyega University staff were sampled. The findings indicate that the country is yet to provide desired level of electricity supply to meet the needs of libraries in the provision of electronic newspaper services in university libraries. It was also revealed that no meaningful e-newspaper services can be recorded without constant supply of electricity. It was therefore recommended that adequate electrical power supply should be provided for provision of effective and efficient newspaper services in university libraries. The literature gap can also be highlighted in the study. The study relates electricity power outage on the provision of electronic newspaper while the performance in terms of profitability of the firm was not known.

Ikhuosho-Asikhia, (2014) investigated the Effect of Generator Usage on Small Scale Businesses in Nigeria. The aim of this study is to analyze the awareness, economic and environmental effects and attitudes of generator usage by small scale businesses and to bring about awareness on the alternatives and benefits of national grid system. To successfully achieve the aim of the study, a hundred small scale business owners in Akure, Ondo State and Benin City, Edo State, both in Nigeria were interviewed face-to-face. The results shows that, $77 \%$ of business owners didn't see generator usage as environ-mental friendly and $71 \%$ also did not see it as yielding profit to their businesses. Considering their annual turnover, $74 \%$ of small scale businesses were willing to pay more for constant electricity supply that is environmental friendly. In addition, businesses with lesser income spend $46 \%$ of their annual income on fuelling and maintenance of their generator. The age range that are into small scale businesses were between $20-24$ years with highest rate of $32 \%$. This shows that more youth are willing to start creative and innovative enterprise to reduce the unemployment rate in the country if there is stable energy supply. This study also suggested some solutions to improve Nigeria's power supply and help businesses to grow. It is expected that this study will help policy makers, stakeholders, investors and business owners to understand the effect of generator usage as an alternative power supply on the economy and the environment. This study only determined the alternative sources of power which is a generator on a small scale business and not on the consistency and output of power supply on sales performance.

\section{Theoretical Framework \\ Economic growth theory}

The neoclassical growth model by Robert Solow and Trevor Winchester Swan (Robert and Barbara, 2009), they advocates that countries can overcome its steady state and continue growing by inventing new technology (Robert \& Barbara, 2009).The economic growth model shows that increase in inputs (land, labour, capital and entrepreneur) and technical improvement determines the extent of economic growth. "The study of economic 
growth across nations and over time- asks whether we produce more because we employ more inputs, or whether the inputs become more productive over time or both" (Burda, 2005), it also refers to the expansion of the country's GDP in a long period of time. There is several stylized fact about economic growth according to Kaldor (1961), but there are some standards that can be observed if we are discussing about economic growth: Population growth, technological progress, and capital accumulation.

When more people are at work, the labour input grows steadily, since they will contribute to wards more working hours. And any increase in labour inputs contributes to a marginal increase in the source of economic growth. For economic growth to be viable there should be a steady state whereby investment should not only pay off capital depreciation but it should involve labour growth in as much as it provides new workers with new or the same technology. New investment is a key progress towards population growth because at the long run, the new investment would be upgraded and improved as well as its services and qualities while new designs can be introduced to expand the quantity of these resources, which would lead to an increase in the economic growth of the country. While in technological progress, all factors of production benefits from it. It involves the development research of new product or service and in the long run it would beapplied in all sector of the economy. Therefore it could be called the input towards better economic conditions.

\section{Methodology}

This section discusses the various steps and procedures the researcher employed in administering, collecting and analysing the data for this research work. The idea behind this section is to explain, as well as give reasons on the procedures used in collecting and analysing data in this study.

\section{Research Design}

Since this study seeks to investigate the effect of power supply fluctuation on frozen food, survey research design was employed. Survey research design was employed because it gives a research the opportunity to sample people's opinion and obtain comment or information from a significant $\mathrm{n}$ umber of respondents. It is also noted that the sole aim of survey study is to examine current opinions, behaviour and other characteristics of a group (Onodugo, Ugwuonah \& Ebinne, 2010).

\section{Study Area}

Aba is a city in the southeast of Nigeria and the commercial centre of Abia State.Aba is made up many villages such as; Aba-Ukwu, Eziukwu-Aba, Obuda-Aba,Umuokpoji-Aba and other villages from Ohazu merged due to administrative convenience. It lies along the west bank of the Aba River, and is at the intersection of roads leading to Port Harcourt, Owerri, Umuahia, IkotEkpene, and IkotAbasi (Hoiberg, \& Dale, 2010). Aba is a major urban settlement and commercial centre in a region that is surrounded by small villages and towns. The indigenous people of Aba are the Ngwa clan of Igbo people. Aba is well known for its craftsmen.

\section{Population of the Study}

The study population consist of 246 frozen food business owners in Aba metropolitan city of Abia State. The population are hereby listed below;

Table 1: Population of selected Frozen Food Dealers in Aba

\begin{tabular}{|r|l|l|}
\hline S/N & Frozen Foods & Respondents \\
\hline 1 & Seafoods Industries Limited & 3 \\
\hline 2 & Mr Chicken Frozen Foods And Provision & 3 \\
\hline 3 & Mummy Favour Cold Stores & 3 \\
\hline 4 & Everyday Frozen Food & 3 \\
\hline 5 & Emy Frozen Chicken & 3 \\
\hline 6 & Nvosi Ventures Nigeria Limited & 3 \\
\hline 7 & Gregil International Limited & 3 \\
\hline 8 & Nocaros Fish Sales Limited & 3 \\
\hline 9 & Nocaros Fish Sales Limited & 3 \\
\hline 10 & Chimax General Merchandise Limited & 3 \\
\hline 11 & F C C International Frozen Foods & 3 \\
\hline 12 & One Spark Foods And Chops Enterprises & 3 \\
\hline 14 & Chimaroke Frozen Food & 3 \\
\hline 15 & Divine Mercy Frozen And Food Stuff & 3 \\
\hline United Brothers Limited & 3 \\
\hline
\end{tabular}




\begin{tabular}{|r|l|l|}
\hline S/N & Frozen Foods & Respondents \\
\hline 16 & Mother Villa & 3 \\
\hline 17 & Gregil International Limited & 3 \\
\hline 18 & Nelad International Company Limited & 3 \\
\hline 19 & Jobkika And Son's Enterprise & 3 \\
\hline 20 & BechyRechy Cooperative Co Nigeria Limited & 3 \\
\hline & Total & $\mathbf{6 0}$ \\
\hline
\end{tabular}

Source: Field Survey, 2021

\section{Sample Size Determination/Sampling Technique}

As explained in population above, a sample population of twenty (20) frozen food firms were selected with a sample size of sixty (60) respondents which was conveniently drawn from our population of interest. However, all elements that constituted the sample size were Director, manager, sales representative who were available in the firm as at the time the questionnaire were distributed in the respective unit/department. This method of nonprobability sampling is referred to as convenience sampling (Ezejelue et al, 2008).

\section{Analysis Technique}

In this study, we adopted a combination of descriptive and inferential statistical tools with statistical package for social sciences (SPSS) version 20 facilitating the analysis. Frequency, means as well as percentages constituted the descriptive statistical tools used to conduct the necessary demographic and univariate analysis. Kendall tau b was employed in analyzing the hypotheses formulated. The questionnaire instrument was based on fivepointLikert scale, which is specified as follows; Strongly Agree (SA) $=5$ point; Agree (A) $=4$ points; Neutral (U) $=3$ points, Disagree $(\mathrm{D})=2$ points, and Strongly Disagree $(\mathrm{SD})=1$.

\section{Data Presentation, Analysis and Discussion of Findings}

A total of sixty (60) copies of the questionnaire were distributed, while fifty four (54) copies were returned and perfectly filled which represents $90 \%$ of the total questionnaire distributed.

Demographic Profile of the respondents

Table 2: Demographic Information on Gender

\begin{tabular}{|l|r|r|}
\hline & \multicolumn{1}{|c|}{ Frequency } & \multicolumn{1}{|c|}{ Percent } \\
\hline MALE & 22 & 41 \\
FEMALE & 32 & 59 \\
Total & 54 & 100.0 \\
\hline
\end{tabular}

Source: SPSS Output, 2021

Table 2 above revealed that (41\%) of the respondents were male frozen food business owners in Aba, while $(59 \%)$ of them were females.

Table 3: Demographic Information on Age

\begin{tabular}{|l|l|l|}
\hline & Frequency & Percent \\
\hline 18-25 years & - & 0 \\
26-30years & 5 & 9.0 \\
31-40years & 16 & 29.6 \\
41-50years & 13 & 24 \\
Above 50years & 20 & 37 \\
Total & 54 & 100 \\
\hline
\end{tabular}

Source: SPSS Output, 2021

From Table 3, the result indicated that $(0 \%)$ of the respondents were within $18-25 \mathrm{yrs} ;(9.0 \%)$ of the respondents were within 26-30yrs; $(29.6 \%)$ of the respondents were within 31-40yrs; (24\%) of the respondents were within 41-50yrs while (37\%) of them were above 50yr. 
Table 4: Demographic Information on Education

\begin{tabular}{|l|r|r|}
\hline & Frequency & Percent \\
\hline WAEC and its equivalent & 9 & 16.6 \\
National Diploma & 12 & 22.2 \\
NCE or its equivalent & 8 & 14.8 \\
University Graduate & 25 & 46.3 \\
Total & 54 & 100.0 \\
\hline
\end{tabular}

Source: SPSS Output, 2021

From the table above, $(16.6 \%)$ of the respondents indicated on WAEC; $(22.2 \%)$ indicated national diploma; $(14.8 \%)$ indicated NCE or its equivalent; while (46.3\%) of the respodents indicated University graduate

Table 5: Demographic Information on Office Position

\begin{tabular}{|l|r|r|}
\hline & Frequency & Percent \\
\hline Director & 21 & 38.8 \\
Manager & 14 & 25.9 \\
Sales Representative & 19 & 35.1 \\
Total & 54 & 100 \\
\hline
\end{tabular}

Source: SPSS Output, 2021

From the above table, $(38.8 \%)$ of the respondents were directors; $(25.9 \%)$ were managers; while $(35.1 \%)$ were sales representatives.

Table 5: Demographic Information on Reception of Power Supply

\begin{tabular}{|l|c|c|}
\hline & Frequency & Percent \\
\hline Weekly & 13 & 24.0 \\
Monthly & 15 & 27.7 \\
Yearly & 5 & 9.3 \\
Daily & 21 & 38.8 \\
Total & 54 & 100.0 \\
\hline
\end{tabular}

\section{Source: SPSS Output, 2021}

From the above table, $(24 \%)$ of the respondents indicated weekly; $(27 \%)$ indicated monthly; $(9.3 \%)$ indicated yearly; (38.8\%) indicated daily while $28(22.4 \%)$.

Table 6: Demographic Information on Alternative Use of Power Supply

\begin{tabular}{|l|c|c|}
\hline & Frequency & Percent \\
\hline Generators & 27 & 50 \\
Solar Panels & 4 & 7.4 \\
Bio Gas & 1 & 9.3 \\
Plants & 8 & 14.8 \\
Inverter & 14 & 25.9 \\
Total & 54 & 100.0 \\
\hline
\end{tabular}

Source: SPSS Output, 2021

From the above table, $(50 \%)$ of the respondents indicated the use of generator; $(7.4 \%)$ indicated the use of solar panels; $(9.3 \%)$ indicated the use of bio gas; $(14.8 \%)$ indicated the use of plants while $(25.9 \%)$ indicated the use of inverter.

Table 6: Percentage response on Erratic Power Supply

\begin{tabular}{|l|l|c|c|c|c|c|c|c|}
\hline S/N & \multicolumn{1}{|c|}{ QUESTIONS } & SA/AA & N & N & D/SD & Total \\
\hline Section B: Erratic Power Supply & & & & & & \\
\hline 1. & $\begin{array}{l}\text { Irregularities in power supply has an adverse effect on } \\
\text { our sales performance }\end{array}$ & 32 & 59.3 & 4 & 7.4 & 18 & 33.3 & 54 \\
\hline $\begin{array}{l}\text { We are not able to reach and sustain our target } \\
\text { customers due to inconsistencies in power supply }\end{array}$ & 26 & 48.1 & 7 & 12.9 & 21 & 38.8 & 54 \\
\hline 3. & $\begin{array}{l}\text { Constant power supply is a vital means of achieving } \\
\text { sales }\end{array}$ & 39 & 72.2 & 2 & 3.7 & 13 & 24.1 & 54 \\
\hline & Grand Total & 97 & 59.5 & 13 & 8.0 & 52 & 31.9 & 163 \\
\hline
\end{tabular}

Table 6 findings above shows the total response of strongly agree (SA), and Agree (A) for the three questionnaire items is $97(59.5 \%) 13(8.0 \%)$ indicated Neutral $(\mathrm{N})$, while $52(31.9 \%)$ indicated Disagree (D) and strongly disagree (SD). This is an indication that the frozen food business owners often times experience 
fluctuations in power supply as indicted by the findings which is above $50 \%$ from the above table. In the submission of Gretchen, (2013). A lack of a "consistent access to reliable power costs businesses and the economy as a whole. Even with access to energy, unreliable power makes operating a business even more challenging than usual. African manufacturing enterprises experience power outages 56 days a year on average. As a result, firms lose six percent of sales revenues in the informal sector. Where back-up generators are limited, losses can be as high as 20 percent. These losses have severe consequences for the health and growth of the wider economy, not to mention the dramatic impact in achieving other development objectives outlined by the Millennium Development Goals"

Table 7: Percentage response on Alternative Power Supply

\begin{tabular}{|c|l|c|c|c|c|c|c|c|}
\hline S/N & \multicolumn{1}{|c|}{ QUESTIONS } & SA/A & \% & N & \% & D/SD & \% & Total \\
\hline & Section B: Alternative Power Supply & & & & & & & \\
\hline 4. & $\begin{array}{l}\text { Generator usage increases the cost of operating } \\
\text { frozen food business }\end{array}$ & 31 & 57.4 & 6 & 11.11 & 17 & 31.5 & 54 \\
\hline 5. & $\begin{array}{l}\text { Alternative power source makes our business } \\
\text { highly competitive in nature }\end{array}$ & 29 & 53.7 & 5 & 9.3 & 20 & 37.0 & 54 \\
\hline 6 & $\begin{array}{l}\text { We have been able to increase our market share } \\
\text { through the use of power generating plant }\end{array}$ & 27 & 80.0 & 6 & 11.11 & 21 & 38.9 & 54 \\
\hline & Grand Total & 53.4 & 17 & 10.4 & 58 & 35.6 & 163 \\
\hline
\end{tabular}

Table 7 findings above shows the total response of strongly agree (SA), and Agree (A) for the three questionnaire items is $87(53.4 \%)$ 17(10.4\%) indicated Neutral (N), while 58 (35.6\%) indicated Disagree (D) and strongly disagree (SD). This is an indication that the use of genarator, plants, solar energy, as a means of generating alternative power supply has increased their operating cost.Nigerians still experience inadequate and unreliable electric power supply characterized by high voltage variations, recurrent black outs and brown outs and pervasive reliance on self-generated electricity (Iwayemi, 2008). Because of the pervasive dependence of the electricity consumers on generators, the Nigerian economy has being described as a generator economy (Ekpo, 2009) exemplified by high operational costs and poor competitiveness.

Table 8: Percentage response on Profitability

\begin{tabular}{|c|c|c|c|c|c|c|c|c|}
\hline $\mathbf{S} / \mathbf{N}$ & QUESTIONS & SA/AA & $\%$ & $\mathbf{N}$ & $\%$ & D/SD & $\%$ & Total \\
\hline \multicolumn{9}{|c|}{\begin{tabular}{|l|} 
Section B: Profitability \\
\end{tabular}} \\
\hline 7. & $\begin{array}{l}\text { There is always an improvement in our sales whenever } \\
\text { there is constant power supply }\end{array}$ & 33 & 61.1 & 7 & 13.0 & 14 & 26.0 & 54 \\
\hline 8. & $\begin{array}{l}\text { We have maximised our profit as a result of regular use } \\
\text { of power supply }\end{array}$ & 44 & 81.5 & - & 0 & 10 & 18.5 & 54 \\
\hline 9. & $\begin{array}{l}\text { There have been an increase in our customer base due } \\
\text { to access to power supply }\end{array}$ & 39 & 72.2 & 4 & 7.4 & 11 & 20.4 & 54 \\
\hline & Grand Total & 116 & 71.2 & 11 & 6.7 & 35 & 21.5 & 163 \\
\hline
\end{tabular}

Table 8 findings above shows the total response of strongly agree (SA), and Agree (A) for the three questionnaire items is $116(71.2 \%) 11(6.7 \%)$ indicated Neutral $(\mathrm{N})$, while $35(21.5 \%)$ indicated Disagree (D) and strongly disagree (SD). This is an indication that the efficient use of power supply has a great influence on the profitability of frozen food business. "Electricity is today's most important energy form for small and medium, and large-scale businesses. Secure supply of electricity at transparent market prices, and high and well-defined quality standards are crucial to economic growth and our whole way of life.Energy supplies have a significant impact on economic activities"(Velasquez and Pitcher, 2010). This is because it is used for diverse purposes extending from production, storage, powering of office equipment and product display. Access to power enlarges the number and diversity of business and job prospects available.

\section{Hypotheses Testing}

$\mathbf{H O}_{1}$ : There is no significant relationship between erratic power supply and profitability of frozen food business in $\mathrm{Aba}$ 
Table 9: Kendall's tau_b Tests Output

\begin{tabular}{|rll|r|r|}
\multicolumn{5}{c}{ Correlations } \\
\hline & & Erratic Power Supply & \multicolumn{2}{l|}{ Profitability } \\
\hline & & Correlation & 1.000 & $.608^{* *}$ \\
Kendall's tau_b & Erratic Power Supply & Coefficient & & .000 \\
& & Sig. (2-tailed) & 54 & 54 \\
& & $\mathrm{~N}$ & $.608^{* *}$ & 1.000 \\
& & Correlation & .000 &. \\
& & Coefficient & 54 & 54 \\
\hline
\end{tabular}

**. Correlation is significant at the 0.05 level (2-tailed).

Source: SPSS Output, 2021

From the result of the above table, the correlation coefficient $(r=0.608)$ between erratic power supply and profitability of frozen food business in Aba, Nigeria is strong and positive. The coefficient of determination $\left(\mathrm{r}^{2}=\right.$ 0.37 ) indicates that $37 \%$ profitability of frozen food business in Aba, can be explained by erratic power supply. The significant value of $0.000(p<0.05)$ reveals a significant relationship. Based on that, the null hypothesis was rejected. Therefore, there is a significant relationship between erratic power supply and profitability of frozen food business in Aba.

$\mathrm{HO}_{2}$ : There is no significant relationship between alternative sources of power supply and profitability of frozen food business in Aba.

Table 11: Kendall's tau_b Tests Output

Correlations

\begin{tabular}{|rl|r|r|}
\hline & & $\begin{array}{c}\text { Alternative source of } \\
\text { power }\end{array}$ & Profitability \\
\hline & Correlation & 1.000 & $.744^{* *}$ \\
Alternative source of power & Coefficient & & .000 \\
& Sig. (2-tailed) &. & 54 \\
& $\mathrm{~N}$ & 54 & 1.000 \\
& Correlation & $.744^{* *}$ & .000 \\
Coefficient & 54 &. \\
& Sig. (2-tailed) & $\mathrm{N}$ & 54 \\
\hline
\end{tabular}

**. Correlation is significant at the 0.05 level (2-tailed).

Source: SPSS Output, 2021

From the result of the above table, the correlation coefficient $(r=0.744)$ between alternative sources of power supply and profitability of frozen food business in Aba is strong and positive. The coefficient of determination $\left(\mathrm{r}^{2}=0.55\right)$ indicates that $55 \%$ profitability can be explained by alternative source of power supply. The significant value of $0.000(p<0.05)$ reveals a significant relationship. Based on that, the null hypothesis was rejected. Therefore, alternative source of power supply significantly affects profitability of frozen food business in Aba.

\section{Summary of Findings}

1. There is a significant relationship between erratic power supply and profitability of frozen food business in Aba.

2. There is a significant relationship between alternative source of power supply significantly affects profitability of frozen food business in Aba.

\section{Conclusion}

This paper investigated the effect of power supply fluctuation on the sales performance of frozen food business in Abia State. The study revealed that erratic power supply and alternative power supply predicts profitability of frozen food business in Aba. Findings from the study revealed that frozen food business owners suffer from erratic power fluctuations either announced or unannounced, and these have adverse effect on the profitability of most of the frozen food surveyed. Lack of a consistent access to reliable power costs businesses and the economy as a whole. Even with access to energy, unreliable power makes operating a business even more challenging than usual. For frozen foods to promote economic growth and development of the country and yield 
more profits, it is essential for them to have access to reliable power and at an affordable cost because power is a necessity to their operations and productivity.

\section{Recommendations}

1. The study therefore seeks to recommend that solar panels should be installed by the government for small consumers of power such as to enable their businesses operate without any setbacks from power crisis and also strategic power plants should be constructed for medium scale industries use.

2. Government should also encourage competition in the power sector, rather than the monopoly of Electricity Company is currently enjoying. We need to be proactive and embrace these renewable energies as quickly as possible as they will lead to decentralization of power supply, create more jobs, lead to lower costs, and cleaner environment.

\section{References}

Adenikinju, A. (2005). Analysis of the cost of infrastructure failures in a developing economy: The case of the electricity sector in Nigeria. African Economic Research Consortium (AERC) Paper 148. Retrieved from http://www.core.ac.uk/download/pdf/6562561.pdf

Aderemi, A.O, Ilori, M.O, Aderemi, H.O and Akinbami, J.F.K (2009), 'Assessment of electrical energy use efficiency in Nigeria food industry', African Journal of Food Science, Vol. 3(8): 206-216.

Aigbokan, B.E. (1999) 'Evaluating Investment on Basic Infrastructure in Nigeria', proceedings of the Eight Annual Conference of the Zonal Research Unit, organized by the Research Department of Central Bank of Nigeria.

Ajao, K.R; Ajimotokan, H.A; Popoola, O.T and Akande, H.F (2009) Electric Energy Supply in Nigeria, Decentralized Energy Approach. Cogeneration and Distributed Generation Journal, Vol. 24, No. 4, October

Burda, M., \&Wyplosz, C. (2005). Macroeconomics: A European text,4th edition. Ohio, USA: Oxford University Press.

Ekpo, A.H. (2009); The Global Economic Crisis and the crisis in the Nigeria Economy. Presidential Address at the 5th Conference of the Nigerian Economic Society, Abuja, Nigeria.

Ellahi, N. (2011). Testing the relationship between electricity supply, development of industrialsector and economic growth: An empirical analysis using time series data for Pakistan.International Journal of Management Science and Engineering Management, 6(4),272-277.

Gretchen K., (2013). Article on 4 ways electricity can jumpstart African economic development.

Ikhuosho-Asikhia, J. O. (2014) Effect of Generator Usage on Small Scale Businesses in Nigeria.Tampere University of Applied Sciences. Degree programme in Environmental Engineering

Iwori, J (2008). Nigeria: How to Resolve Power Problem. This Day News online, July 12, 2008. www.thisdayonline.com

Kaldor, N. (1961). Capital accumulation and economic growth. In F. A. Lutz \& D. C. Hague (Eds.), Theory of Capital (177-222). London: Macmillan.

MAN (2005), Manufacturers Association of Nigeria -Membership profile, available from: http://www.manufacturersnigeria.org/membership.htm.

NiyiAwofeso. Generator Diesel Exhaust: a Major Hazard to Health and the Environment in Nigeria. American Journal of Respiratory and Critical Care Medicine, Vol. 183, No. 10 (2011), pp. 1437.

RaunoPaakonen. Noise and Radiation Lecture Notes, Tampere University of Applied Science, Environmental Engineering Department, October, 2012.

Robert W. D. and Barbara J. S. (2009) History of Political Economy41 (annual suppl.) DOI 10.1215/001827022009-019, Duke University Press

This DayLive Online Newspaper, Nigeria, January 21st, 2013. Issues in the New Poverty Report.

Total Nigeria. 2007. History of Nigeria

Toyin D. (2014).The Effects of Electricity Power Outage on The Provision of Electronic Newspaper Services Samuel Adegboyega University, Ogwa, Edo State, NIGERIA. Samuel Adegboyega University, OgwaEdo State, Nigeria

Uchendu, O.A. (1993); The economic cost of electricity outages: Evidence from a sample study of Industrial and commercial firms in Lagos, Nigeria. Nigerian Journal of Economics and Social Studies. Vol. 1, Pp 50-81.

Ukpong, I.I. (1973); The economic consequences of electric power failures. The Nigerian Journal of Economic and Social Studies. Vol. 2, Pp 90-120.

Velasquez, J.R.C., \&Pichler, B. (2010). China's increasing economy and the impacts on its energy. EstudiosGerenciales, 26(117), 131-143.

World Bank (2005). World development report. Washington DC: The World Bank. Retrieved from wwwwds.worldbank.org/2005/20050920110826/.../322040 World 